\title{
O USO VARIÁVEL DE ARTIGO DEFINIDO DIANTE DE PRONOME POSSESSIVO NA VARIEDADE URBANA DO PORTUGUÊS DE SÃO TOMÉ
}

\author{
Danielle Kely GOMES \\ Livia Rodrigues CORDEIRO²
}

\section{DOI: http://dx.doi.org/10.21165/gel.v18i3.3159}

Resumo: Neste artigo investiga-se o comportamento do artigo definido diante de pronomes possessivos na variedade urbana do Português de São Tomé (PST). Para tanto, utilizam-se dados recolhidos em 17 entrevistas, realizadas em 2009 na capital do arquipélago de São Tomé e Príncipe. Os inquéritos pertencem ao corpus Variedades do Português (VAPOR), do Centro de Linguística da Universidade de Lisboa. Toma-se como base o aporte teórico-metodológico da Teoria da Variação e Mudança (WEINREICH; LABOV; HERZOG, 2006 [1968]), com o intuito de identificar os condicionamentos linguísticos e sociais que concorrem para a ausência do artigo definido na variedade analisada. Os resultados revelam que, na variedade urbana do PST a presença do artigo diante de pronomes possessivos é um fenômeno produtivo (54\%), sendo a ausência nesse contexto condicionada por restrições vinculadas à natureza do sintagma em que figura 0 pronome possessivo, à função sintática do sintagma em que figura o pronome possessivo, ao tipo de posse e à escolaridade do informante. A análise multivariável indicou que os dados não são sensíveis à influência da frequência de uso do crioulo Forro, o que contraria a hipótese inicialmente formulada.

Palavras-chave: Artigo Definido. Pronomes Possessivos. Variação. Português de São Tomé.

\footnotetext{
1 Universidade Federal do Rio de Janeiro (UFRJ), Rio de Janeiro, Rio de Janeiro, Brasil; daniellekgomes@letras.ufrj.br, https://orcid.org/0000-0001-6335-1674

2 Universidade Federal do Rio de Janeiro (UFRJ), Rio de Janeiro, Rio de Janeiro, Brasil; liviarodrigues20@letras.ufrj.br, https://orcid.org/0000-0002-7280-5225
} 
- O uso variável de artigo definido diante de pronome possessivo na variedade urbana do Português de São Tomé

\title{
THE VARIABLE USE OF THE DEFINITE ARTICLE IN FRONT OF A POSSESSIVE PRONOUN IN THE URBAN VARIETY OF SANTOMEAN PORTUGUESE
}

\begin{abstract}
This paper investigates variation in the use of the definite article in front of possessive pronouns in the urban variety of Santomean Portuguese (STP). We use data from 17 interviews conducted in 2009 in the capital of São Tomé and Príncipe. The surveys are part of the Variedades do Português (VAPOR) corpus, from Center of Linguistics of the University of Lisbon. Our study is based on the theoretical-methodological contribution of the Theory of Variation and Change (WEINREICH; LABOV; HERZOG, 2006 [1968]), in order to identify the linguistic and social factors that contribute to the absence of the definite article in the analyzed data. The results reveal that, in the urban variety of STP, the presence of the article before possessive pronouns is a productive phenomenon (54\%), and the absence in this context is constrained by the nature of the phrase in which the possessive pronoun occurs, the syntactic function of the phrase in which the possessive pronoun appears, the type of possession, and the informant's education. Multivariable analysis indicated that the data are not sensitive to the influence of the frequency of use of Forro, which contradicts the hypothesis initially formulated.
\end{abstract}

Keywords: Definite Article. Possessive Pronouns. Variation. Santomean Portuguese.

\section{Introdução}

O uso de artigos diante de pronomes possessivos (meu livro x o meu livro) é uma regra variável no que se refere às variedades do Português Brasileiro (doravante PB). Diversos trabalhos, inspirados na análise apresentada em Silva (1982), descrevem a dinâmica da variação no PB.

No âmbito do Português Europeu (daqui por diante, PE), as investigações disponíveis revelam que não há variação no uso de artigos diante de possessivos na variedade europeia, que se define pelo uso categórico do determinante definido diante de possessivos. A ausência de artigo nesse contexto só é possível em construções cristalizadas (Nossa Senhora, Vossa Senhoria) e em estruturas vocativas (Não, minha senhora!), "sendo a não ocorrência do artigo definido nas restantes frases sentidas como anômala" (INVERNO; SWOLKIEN; 2003, p. 182).

De modo a ampliar o espectro de descrição de outras variedades do Português além do eixo PB-PE, propõe-se, neste trabalho, a descrição do comportamento de artigos definidos diante de pronomes possessivos em dados representativos de uma variedade 
africana do Português, a partir da análise da variedade urbana do Português de São Tomé (doravante PST). A investigação justifica-se pela caracterização da comunidade investigada: a realidade sociolinguística da variedade - marcada pela convivência entre o Português e crioulos de base lexical portuguesa (especificamente o Forro) - revela questões importantes para a descrição da regra variável na localidade.

Busca-se contribuir, com a presente investigação, para a descrição de uma regra linguística que demarca diferenças entre variedades do Português e também se toma por propósito ampliar o escopo de análises de processos linguísticos em realidades marcadas pelo multilinguismo, para verificar de que maneira as relações de contato entre línguas atuam na modelagem da gramática de comunidades de fala.

O artigo se organiza de acordo com as seções a seguir, apresentadas em sequência: apresenta-se o "estado da arte" sobre a variação no uso de artigos definidos diante de pronomes possessivos em Português, a partir da síntese de trabalhos sobre o tema; propõe-se um panorama breve sobre aspectos sociolinguísticos da comunidade de fala em análise; indicam-se os referenciais teóricos e a metodologia adotados para a investigação; discutem-se os resultados da análise quantitativa e tecem-se considerações sobre a investigação realizada neste artigo.

\section{A variação no uso de artigos diante de possessivos em português}

No que se refere às variedades do PB, há uma farta descrição acerca da regra variável de uso de artigo diante de pronomes possessivos. Essas investigações, apesar de indicarem índices percentuais variáveis no uso de artigo definido nesse contexto, apresentam uma reflexão consistente sobre a interação entre restrições linguísticas e sociais para a dinâmica da variação. No âmbito da variedade europeia, contudo, os trabalhos sobre o tema são unânimes em destacar que há uma regra categórica de uso de artigo diante de possessivos. Já no que tange às variedades africanas do Português, os trabalhos sobre o tema são escassos, se concentram em comunidades isoladas, e se pautam na descrição de variedades parcialmente reestruturadas (cf. LORENZINO, 1996; FIGUEIREDO, 2019). A seguir, um breve panorama de investigações que atestam a complexidade do fenômeno em foco.

Silva (1982), em um trabalho pioneiro que se dedica a investigar a variação no uso de artigo diante de possessivos - em uma análise diacrônica e contrastiva entre variedades do PB e do PE -, revela que as variedades tomam direções opostas no que se refere ao uso do artigo nesse contexto. Para a análise da variedade europeia, a autora realizou uma investigação de tempo real de longa duração (em textos escritos entre os séculos XIV e 
- O uso variável de artigo definido diante de pronome possessivo na variedade urbana do Português de São Tomé

$X X)$; para análise do $\mathrm{PB}$, o trabalho parte de uma análise diacrônica em textos escritos dos séculos XIX e XX e uma descrição sincrônica de amostras de fala do Projeto NURC. Os resultados relativos ao PB indicam que, na perspectiva diacrônica, houve um ligeiro aumento das taxas de uso de artigo diante de possessivos entre os séculos XIX e XX (variação entre $30 \%$ e $40 \%$ nos dois recortes temporais investigados), o que revela uma estabilidade na regra variável.

A autora controlou as variáveis linguísticas que poderiam condicionar a realização de artigo diante dos possessivos, tais como a especificidade do possuidor e o número do sintagma. Sobre a atuação da primeira variável, Silva (1982) afirma que os dados 'não específicos' indicam estruturas em que "o informante não necessita destacar elemento(s) do conjunto: a informação ou não é necessária ou, pelo contrário, já está bem clara" (SILVA, 1982, p. 271). De forma bastante uniforme, os dados analisados se mostraram sensíveis à especificidade do referente possuído: a variante possuído 'específico' se mostrou favorecedora do uso de artigo, ao passo que a variante 'não específico' desfavoreceu a presença de artigo. No âmbito da atuação da variável número, o plural favoreceu a ausência de artigo - o que em certa medida "reforça" o efeito da variável 'especificidade', uma vez que o plural demarca uma "definição intrínseca" que dispensa o uso de artigo. Nos termos de Silva (1982, p. 367), "o plural refere-se ao conjunto inteiro. Não necessitando de artigo para expressar veladamente a idéia de todos, o artigo torna-se redundante".

Lucchesi (1993), em um trabalho que descreve o sistema de artigos em crioulos de base lexical portuguesa de Cabo Verde e São Tomé, estabelece uma generalização acerca do comportamento dos artigos definidos nas variedades do PB e do PE. O autor afirma que "em Portugal e no sul do Brasil, o artigo definido e o possessivo normalmente coocorrem enquanto no norte e no nordeste do Brasil o artigo é normalmente apagado" (LUCCHESI, 1993, p. 91, tradução nossa3). Essa tendência também foi observada por Callou e Silva (1997), que identificam um continuum de frequência de uso de artigo definido frente a possessivos. As autoras atestam que o continuum se estabelece conforme se avança da região nordeste para o extremo sul do Brasil, conforme se se expressa na tabela 1, a seguir.

3 No original: "In Portugal and the south of Brazil, the definite article and the possessive normally co-occur, whereas in northern and northeast Brazil the article is normally absent.". 
Tabela 1. Continuum de uso de artigos definidos diante de pronomes possessivos nas capitais do Projeto NURC/BR

\begin{tabular}{c|c}
\hline Regiões & Frequência \\
\hline RE & $60 \%$ \\
\hline SSA & $66 \%$ \\
\hline RJ & $70 \%$ \\
\hline SP & $70 \%$ \\
\hline POA & $79 \%$ \\
\hline
\end{tabular}

Fonte: Leite e Callou (2010, p. 53).

Menon (2016), ao realizar o mapeamento geográfico da variável artigo diante de pronomes possessivos em uma capital de um estado do Nordeste (João Pessoa) e uma do Sul do país (Curitiba), constatou um certo equilíbrio entre os índices de presença (54\%) e ausência (46\%) de artigo em João Pessoa. Já em Curitiba, os resultados revelaram que o uso de artigo (63\%) era mais saliente do que a ausência do determinante (37\%). O mapeamento de Menon, ainda que indique diferenças percentuais na distribuição da variação, acaba por reforçar a proposta de continnum elaborada por Callou e Silva (1997), na medida em que a capital do Nordeste apresenta uma frequência de uso do artigo menor do que a verificada na capital da região Sul.

Os trabalhos de Schei (2009) e Magalhães (2011) trazem contributos importantes para a compreensão do fenômeno no âmbito do PE. Schei (2009), apesar de concentrar a investigação no comportamento de artigo definido diante de possessivo em sete romances brasileiros, realizou uma análise do fenômeno em romances portugueses dos séculos XIX e XX. A autora verificou que o emprego de artigo definido no Português Europeu caracteriza-se em uma regra categórica, tendência notoriamente distinta da que se observa no âmbito do Português do Brasil.

Magalhães (2011) faz um mapeamento diacrônico da generalização do emprego de artigo definido diante de possessivos na variedade europeia, a partir da análise de textos escritos entre os séculos XVI e XIX. Os resultados revelaram duas tendências distintas para a evolução do fenômeno: i) em sintagmas nominais, a realização variável de artigo é atestada já no século XVI. No entanto, a variação se torna rarefeita em meados do século XVII, tendo seu desaparecimento total no século XVIII. No século XIX, há uma generalização significativa do emprego de artigo definido, de modo a evidenciar seu uso categórico; ii) em sintagmas preposicionais, a ausência de artigo diante de possessivo no século XVI era categórica. No século XVII, os dados atestam o início da variação nesse contexto, tendência que perdurou até o século XIX. 
- O uso variável de artigo definido diante de pronome possessivo na variedade urbana do Português de São Tomé

Os estudos apresentados até aqui se dedicam a investigar corpora escritos e amostras de fala urbana das variedades brasileira e europeia. Entretanto, cabem considerações sobre estudos que se debruçam em variedades reestruturadas do Português. Destacamse, nesse âmbito, os trabalhos de Baxter e Lopes (2009), sobre o falar de Helvécia, e Figueiredo (2019), sobre o Português de Almoxarife.

Baxter e Lopes (2009) descrevem o comportamento de artigo definido no dialeto de Helvécia - uma comunidade linguística afro-brasileira localizada no sul do estado da Bahia. Os autores observaram, no que se refere à variável presença de outros modificadores em SN's, um efeito contrastivo entre as variantes presença de oração relativa e ocorrência de pronomes possessivos em sintagmas nominais. A presença de uma oração relativa não foi um condicionamento que atuou na inibição do uso de artigo definido. Já a presença de pronomes possessivos no sintagma nominal foi uma condição que atuou para desfavorecer o uso do artigo definido. Uma provável explicação para a diferença no comportamento desses dois condicionamentos que atuam na delimitação da referência pode ser atribuída ao fato de que os possessivos atuariam de forma mais consistente na atribuição da referência, sendo a ocorrência de artigo definido nesse contexto uma redundância.

No português de Almoxarife (PA), comunidade localizada em São Tomé, Figueiredo (2019) verificou que os homens tendiam a empregar mais o artigo em sintagmas nominais do que as mulheres. Uma provável justificativa para o comportamento dos informantes do sexo masculino pode estar atrelada ao fato de que os homens têm mais contato com o mundo exterior à comunidade, devido aos fluxos de migração nos centros urbanos, à inserção destes indivíduos no exército e ao fator maior escolarização destes. As mulheres, ao contrário, apresentam maior variação quanto ao uso de artigo definido em sintagmas nominais, uma vez que tendem a se concentrar mais na comunidade.

No que se refere à atuação da variável social idade do informante, Figueiredo (2019) comparou a variedade do Português de Almoxarife (PA) com os trabalhos sobre as variedades do Português dos Tongas, Roça Monte Café, São Tomé (PT) (BAXTER; LOPES; 2005, 2006) e do Português rural de Helvécia, Bahia (PHEL) (BAXTER; LOPES, 2009). $\mathrm{O}$ autor identificou diferença geracional entre a primeira variedade e as duas últimas, porque "o PT e o PHEL apresentam aquisição diacrónica semelhante, denotando um crescente uso do artigo definido, ou seja, aquisição em direção à nivelação com a variante padrão" (FIGUEIREDO, 2019, p. 373). Não foi possível notar essa tendência no PA, já que a comunidade esteve isolada por muito tempo, o que provavelmente motivou uma estabilidade na variação do emprego de artigo definido em sintagmas nominais. 
Os trabalhos resenhados nesta seção atestam a complexidade no uso variável de artigo diante de pronomes possessivos. Neste artigo, buscam-se lançar novas luzes sobre o papel do multilinguismo na estrutura da variação. Para tanto, torna-se essencial uma reflexão sobre a história sociolinguística da comunidade de fala investigada, na medida em que o conhecimento dos aspectos sociais e históricos na base da formação do PST oferecem subsídios para a formulação das hipóteses e análise quantitativa dos dados.

\section{Breves considerações sobre a história sociolinguística do Português de São Tomé}

O arquipélago de São Tomé e Príncipe é marcado pela coexistência entre o Português e quatro línguas crioulas de base portuguesa - três autóctones (Forro/Santome, Angolar, Lung'ie) e o Kaboverdiano, originário da Alta Guiné (SANTIAGO; AGOSTINHO, 2020, p. 40). O multilinguismo da comunidade é resultado de uma série de eventos históricos que ocorreram ao longo dos séculos e que tornaram a região um local onde o contato entre línguas é saliente. Tais fatores históricos estão associados a dois ciclos econômicos, frutos de dois processos de colonização na ilha. O primeiro ciclo é marcado pelo cultivo de cana-de-açúcar, entre o final do século XV e o fim do século XVI. O segundo ciclo é caracterizado pela cultura de café e cacau em meados do século XIX.

Segundo Gonçalves e Hagemeijer (2015, p. 88), durante o primeiro ciclo, o contato entre portugueses e africanos motivou o surgimento de um pidgin, para que houvesse uma comunicação minimamente possível entre os grupos que se concentravam em um contexto marcado pela convivência entre várias línguas. Ainda nesse primeiro momento, conforme apontam os autores, a difusão desse pidgin contribuiu para a origem de um crioulo de base lexical portuguesa. Nesse sentido, "a continuação no tempo desta protolíngua é a língua que hoje é conhecida como Forro, o crioulo maioritário de São Tomé e Príncipe" (GONÇALVES; HAGEMEIJER, 2015, p. 88).

Após um período inicial de sucesso na atividade colonial em São Tomé, o processo sofre um revés. Na verdade, há uma interrupção na colonização da ilha após o breve período de prosperidade no século XVI, por conta do êxodo dos colonizadores portugueses para o Brasil. A migração dos colonizadores se deu em função de rebeliões de africanos escravizados e de ataques de saqueadores, o que tornou impraticável a manutenção dos portugueses na ilha (LUCCHESI, 1993). A migração dos portugueses para o Brasil ecoa no processo de crioulização, pois - como aponta Ferraz (1976, p. 35, tradução nossa4) -, "este fator, ocorrendo no estágio inicial da formação do crioulo, contribuiu para um substrato

4 No original: "This factor, occurring at an early stage in the formation of the Creole, contributed to a pronounced African substratum, not only in the Creole of São Tome, but also in the Creoles of Principe and Anno-bón, islands which were dependent on São Tome.". 
- O uso variável de artigo definido diante de pronome possessivo na variedade urbana do Português de São Tomé

africano pronunciado, não somente em São Tomé, mas também nos crioulos do Príncipe e Ano-Bom, ilhas dependentes de São Tomé".

O segundo ciclo também é marcado por acontecimentos históricos que mudaram o panorama linguístico da comunidade são-tomense, dentre eles, destacam-se a abolição da escravidão (1869) e a formalização jurídica (1875), que concedia a liberdade aos escravos. Isso configurou uma grave crise de mão-de-obra em São Tomé, porque "os escravos recém-libertos se recusaram a trabalhar nas empresas agrícolas" (2015, p. 89). Para solucionar esse problema, recorreu-se ao regime de contrato, para o recrutamento de trabalhadores de outras colônias portuguesas em África (Angola, Cabo Verde e Moçambique). De acordo com Gonçalves e Hagemeijer (2015), até o século XVIII, o crioulo era a língua majoritariamente falada, mas, devido à chegada desses contratados, essa realidade linguística mudou: os contratados adotam o Português como L2 e não o crioulo.

No decorrer do processo de colonização na ilha, o Português era a língua materna de uma pequena parcela da população. Contudo, o Estado Novo português (1933-1974) forjou a criação de uma política linguística que consolidava a língua portuguesa na região, e, por efeito, criava condições objetivas para a repressão às línguas locais. Mesmo anterior à independência, em 1975, e à determinação do Português como língua oficial de São Tomé, o Português já era língua materna da maior parte da população, como também era utilizado em sistemas de radiodifusão e já estava implementado como norma de referência no processo de escolarização.

É importante destacar, todavia, que o rótulo "Língua Portuguesa" em São Tomé e Príncipe recobre um leque de situações linguísticas que contribuem para a realidade plural da comunidade. Nesse sentido: (i) o Português Europeu é a "língua oficial"; (ii) paralelamente, verifica-se a existência de uma variedade fortemente condicionada pelo contato entre o português e o Forro - crioulo de base lexical portuguesa que funciona como língua materna de alguns santomenses e como L2 de $36.2 \%$ dos falantes ${ }^{5}$ (INE 2012); também se destacam (iii) as variedades forjadas pelo contato entre o Português e os demais crioulos.

Dessa feita, a descrição linguística do PST não pode prescindir dos efeitos da relação entre a língua oficial padrão - o Português Europeu - e a variedade "veicular" - "um falar de características fonológicas e morfossintáticas próprias, cujos desvios em relação à norma

5 Dados do IV Recenseamento Geral da População e Habitação (documento 12 - "Características Educacionais da População"). Os documentos estão disponíveis em https://www.ine.st/index.php/publicacao/ documentos/category/72-relatorio-tematicos-recenseamento-2012. Acesso em: 28 ago. 2021. 
são significativos, em que se assiste a uma tendência cada vez maior para a contaminação do código escrito para o código oral" (AFONSO, 2009, p. 70). É essa variedade que configura a língua materna da maioria da população são-tomense - resultado do processo de contato entre o Português e as línguas crioulas, e se caracteriza por uma série de traços linguísticos que o diferenciam do Português Europeu ${ }^{6}$.

\section{Aportes teóricos e metodologia}

Para a descrição da regra variável de uso de artigos definidos diante de pronomes possessivos, recorre-se ao modelo teórico postulado pela Sociolinguística Variacionista, proposta originalmente por Weinreich, Labov e Herzog (2006 [1968]) e refinado em trabalhos posteriores de Labov $(1972,1994,2001)$. O modelo parte do princípio de que todas as línguas são suscetíveis aos processos de variação e mudança. Tendo em vista isso, os autores propõem que:

(i) todos os sistemas linguísticos são caracterizados por uma heterogeneidade inerente, ordenada e sistemática, e

(ii) o caráter heterogêneo das línguas não prejudica seu funcionamento.

Para a compreensão de como se configura a diferenciação ordenada dentro dos sistemas linguísticos, os autores postulam que é preciso investigar a relação entre língua e os contextos sociais nos quais ela é utilizada. Desse modo, assumem que o objeto de análise é a comunidade de fala, porque é por meio dela que é possível compreender os processos de variação e mudança. Assim, pode-se identificar fenômenos variáveis como também padrões de variação dentro de uma comunidade linguística.

Além de um modelo de descrição da variação, é importante ressaltar que esta investigação parte de quadros teóricos que lidam com questões de contato entre línguas (WEINREICH, 1953; THOMASON; KAUFMAN, 1988; WINFORD, 2003; LUCCHESI; BAXTER, 2009; entre tantos outros), na medida em que se toma por hipótese que o contato entre o Português e as línguas crioulas - em especial destaque para o Forro - molda a gramática da comunidade de fala são-tomense. Conforme destacado na seção anterior, entende-se que a variedade do Português falada na comunidade apresenta um conjunto de traços linguísticos (fonológicos e morfossintáticos) que a distanciam do Português Europeu.

6 Lorenzino (1996, p. 14) denomina como "português aéreo" a variedade forjada na situação de contato entre o Português e as línguas locais. 
- | O uso variável de artigo definido diante de pronome possessivo na variedade urbana do Português de São Tomé

A descrição da regra variável parte da análise de 517 dados, extraídos de dezessete entrevistas - organizadas de acordo com as variáveis sociais sexo, escolaridade e faixa etária. Os inquéritos pertencem ao corpus Variedades do Português (VAPOR), do Centro de Linguística da Universidade de Lisboa. As gravações foram feitas na capital de São Tomé e Príncipe, no ano de 2009. Os dados que comportam o corpus deste trabalho foram analisados estatisticamente com o auxílio do programa Goldvarb-X.

As variáveis linguísticas controladas neste trabalho verificam em que medida questões relacionadas à natureza do sintagma, ao tipo de posse, à função sintática do sintagma, ao tipo de verbo com que se relaciona o sintagma possessivo, à pessoa do discurso e à presença de elementos entre o possessivo e o nome atuam para favorecer a ausência do artigo definido nos dados analisados. No que se refere às variáveis sociais, controlam-se as restrições que figuram na estratificação da amostra, além da variável frequência de uso do crioulo Forro ${ }^{7}$. No quadro 1, a seguir, elencam-se os condicionamentos investigados.

Quadro 1. As variáveis investigadas

\begin{tabular}{|c|c|}
\hline \multirow{4}{*}{ Variáveis linguísticas } & Tipo de sintagma \\
\cline { 2 - 3 } & Tipo de preposição \\
\cline { 2 - 3 } & Tipo de verbo \\
\cline { 2 - 2 } & Pessoa do discurso \\
\cline { 2 - 2 } & Tipo de posse \\
\cline { 2 - 2 } Variáveis sociais & Presença de elemento interveniente entre o possessivo e o nome \\
\cline { 2 - 2 } & Sexo \\
\cline { 2 - 2 } & Faixa etária \\
\cline { 2 - 2 } & Escolaridade \\
\cline { 2 - 2 } & Frequência de uso do crioulo Forro \\
\hline
\end{tabular}

Fonte: Elaboração própria.

Assume-se como valor de aplicação a ausência de artigo definido justamente para tentar verificar se as questões relacionadas ao contato entre o Português e o Forro vão condicionar a dinâmica da regra variável. Segundo Lucchesi (1993), no Forro não há artigos definidos. É importante ressaltar que a partícula "se", conforme aponta Ferraz (1979), ora pode desempenhar a função de demonstrativo, ora pode cumprir a função de artigo

7 Brandão (2016, p. 91) descreve as seguintes variantes para a variável Frequência de uso do crioulo Forro: "frequência (a) zero/baixa, referente aos indivíduos que se expressam fundamentalmente em português; (b) média, relativa aos indivíduos que se expressam em português, mas dominam um crioulo e dele fazem uso eventualmente; (c) alta, abarcando os indivíduos que, embora falem o português e o tenham como L1, se expressam, regularmente, num crioulo." 
definido. Outra característica do crioulo Forro que se deve levar em consideração é o fato de que a presença de elementos modificadores no sintagma nominal - como adjetivos, orações relativas e pronomes possessivos - pode inibir a presença do demonstrativo (LUCCHESI, 1993). Tendo em vista esses aspectos relativos ao crioulo Forro, parte-se da hipótese de que a não existência de artigo definido no crioulo são-tomense poderia contribuir para a não ocorrência de artigo definido diante de pronomes possessivos na norma veicular são-tomense.

\section{Resultados}

Nesta seção, apresentam-se e discutem-se os resultados da análise estatística. Toma-se por hipótese que o emprego de artigo definido diante de pronomes possessivos se configura como uma regra variável na variedade urbana são-tomense. Os dados (1) e (2), a seguir, ilustram as variantes ausência e presença de artigo definido em análise.

$$
\text { Meu pai sempre foi comerciante e ainda é. (ST-A-3-m) }
$$

$$
\text { a língua crioulo, ela existe, porque existem os seus falantes. (ST-A-3-h) }
$$

Na tabela 2, abaixo, expressam-se os índices gerais de distribuição das variantes nos dados analisados

Tabela 2. Índices gerais referentes à variação de artigo definido diante de possessivos na variedade do Português de São Tomé

\begin{tabular}{|c|c|c|}
\hline Variante & Apl/T & $\mathbf{\%}$ \\
\hline Ausência de artigo diante do possessivo & $235 / 517$ & $45 \%$ \\
\hline Presença de artigo diante do possessivo & $282 / 517$ & $54 \%$ \\
\hline
\end{tabular}

Fonte: Elaboração própria.

Na Tabela 2, é possível observar que, no PST, a presença de artigo definido diante de pronomes possessivos é um fenômeno produtivo (54\%). Contudo, os dados gerais evidenciam tendências muito distintas das quais se verificam no Português Europeu, que constitui sua norma de referência - em que o uso de artigo definido no referido contexto caracteriza-se como uma regra categórica (SCHEI, 2009; MAGALHÃES, 2011). Os resultados expostos na tabela acima revelam um comportamento mais próximo às tendências observadas no Português do Brasil, em que a realização variável de artigo definido é bastante saliente entre as regiões do país (CALLOU; SILVA, 1997).

No Quadro 2, estão expressas as restrições que foram selecionadas pelo programa Goldvarb-X como significativas para a implementação da variante em que se verifica a ausência de artigo diante de possessivos. 
- O uso variável de artigo definido diante de pronome possessivo na variedade urbana do Português de São Tomé

Quadro 2. Variáveis estatisticamente relevantes para a ausência de artigo definido diante de possessivos

\begin{tabular}{|c|c|c|c|}
\hline \multicolumn{4}{|c|}{$\begin{array}{c}\text { Escolaridade } \\
\text { Tipo de sintagma } \\
\text { Função sintática do sintagma em que figura o pronome possessivo } \\
\text { Tipo de posse }\end{array}$} \\
\hline Apl/T & Input Inicial & $\begin{array}{c}\text { Input da rodada } \\
\text { selecionada }\end{array}$ & $\begin{array}{c}\text { Significância da rodada } \\
\text { selecionada }\end{array}$ \\
\hline $235 / 517=45 \%$ & .455 & .437 & .000 \\
\hline
\end{tabular}

Fonte: Elaboração própria.

No Quadro 2, acima, observa-se que, das onze variáveis independentes postuladas para a investigação do fenômeno, somente quatro - uma social e três linguísticas - foram indicadas como relevantes estatisticamente para a ausência de artigo definido diante de pronomes possessivos. A seguir, apresentam-se os resultados estatísticos para cada variável selecionada e a interpretação desses dados à luz das hipóteses de investigação.

No que se refere à correlação entre nível de escolarização do informante e a ausência do artigo definido diante de possessivo, a Tabela 3, a seguir, apresenta os índices percentuais e os pesos relativos.

Tabela 3. Efeito da variável escolaridade sobre a ausência de artigo definido

\begin{tabular}{c|c|c}
\hline Nível & Apl/T & PR \\
\hline básico & $96 / 126=73,8 \%$ & .772 \\
\hline intermediário & $70 / 174=40,2 \%$ & .435 \\
\hline superior & $72 / 217=33,2 \%$ & .378 \\
\hline
\end{tabular}

Fonte: Elaboração própria.

Conforme o exposto na Tabela 3, os índices de ausência de artigo decrescem na medida em que se avançam pelos níveis de escolarização: quanto menor a escolaridade do indivíduo, maior é a implementação de sintagmas possessivos sem presença de artigo definido. Cumpre destacar que esses índices corroboram os resultados obtidos na análise feita sobre o comportamento de cada informante, que será apresentada posteriormente neste artigo.

$\mathrm{Na}$ tabela 4, são expostos os índices percentuais e os pesos relativos acerca da variável tipo de sintagma. 
Tabela 4. Efeito da variável tipo de sintagma sobre a ausência de artigo definido

\begin{tabular}{c|c|c}
\hline Tipo & Apl $/ \mathbf{T}$ & PR \\
\hline Sintagma nominal & $187 / 345=52,2 \%$ & $\mathbf{. 6 6 9}$ \\
\hline Sintagma preposicional & $48 / 172=27,9 \%$ & .196 \\
\hline
\end{tabular}

Fonte: Elaboração própria.

Os resultados expressos na tabela acima revelam que os falantes são-tomenses tendem a não realizar os artigos definidos quando os pronomes possessivos se encontram em sintagmas nominais (.669). Essa tendência também pode ser observada no trabalho de Baxter e Lopes (2009), sobre a variação no emprego de artigos definidos em sintagmas nominais no dialeto de Helvécia. Os autores puderam notar que nessa estrutura a presença de pronomes possessivos demonstrou ser um fator considerável para a não realização do artigo definido, já que o possessivo tem referência definida suficiente capaz de dispensar o artigo em sintagmas nominais. Portanto, é possível perceber que o artigo definido está mais propício à não realização em sintagmas nominais do que em sintagmas preposicionais; estes, conforme apontam os dados na tabela 4, atuam como bloqueadores do fenômeno investigado. A seguir, é apresentado o exemplo (3) que ilustra o contexto morfossintático que bloqueia a presença de artigos definidos diante de pronomes possessivos.

(3) pra outros país é perto de qualquer maneira, nossa realidade são zonas longínquas e eu fui chamado agora (ST-B-3-h)

Em relação à atuação da variável função sintática do sintagma possessivo, apresentam-se, na Tabela 5 - a seguir, os índices percentuais e os pesos relativos.

Tabela 5. Efeito da variável função sintática do sintagma em que figura o pronome possessivo sobre a ausência de artigo definido

\begin{tabular}{c|c|c}
\hline Função & Apl/T & PR \\
\hline Adjunto adverbial & $40 / 90=44,4 \%$ & $\mathbf{. 7 5 2}$ \\
\hline Oblíquos nucleares & $22 / 62=35,5 \%$ & $\mathbf{. 6 9 1}$ \\
\hline Predicativo & $12 / 18=66 \%$ & $\mathbf{. 6 6 7}$ \\
\hline Objeto indireto & $1 / 6=16,7 \%$ & .499 \\
\hline Adjunto adnominal & $5 / 36=13,9 \%$ & .419 \\
\hline Objeto direto & $46 / 97=47,4 \%$ & .409 \\
\hline Sujeito & $106 / 186=57 \%$ & .405 \\
\hline Construção de tópico & $3 / 22=13,6 \%$ & .124 \\
\hline
\end{tabular}

Fonte: Elaboração própria. 
- O uso variável de artigo definido diante de pronome possessivo na variedade urbana do Português de São Tomé

Os resultados expressos na Tabela 5, acima, demonstram que as funções que mais propiciam a não realização de artigo definido diante de possessivo na variedade sãotomense correspondem às variantes adjunto adverbial (.752), oblíquos nucleares (.691) e predicativo (.667). É interessante observar que há uma gradação entre essas funções para a ausência de artigo definido diante de pronomes, indicando que a variante adjunto adverbial apresenta um valor considerável para a não realização do determinante. As demais funções sintáticas controladas se mostraram como contextos de bloqueio para a não ocorrência do artigo. Os exemplos de (4) a (6), a seguir, ilustram os contextos sintáticos que favorecem a não ocorrência de artigos definidos.

(4) respondi ele em nosso português (ST-A-3-h)

(5) fui trabalhar na casa de pessoa porque salário era muito baixo, também com a ajuda de minha avó sempre ela apoiou-me (ST-A-1-m)

(6) Se você não é meu homem, eu vou dançar com você (ST-B-1-m)

Na Tabela 6, apresentam-se os índices percentuais e os pesos relativos associados à variável tipo de posse.

Tabela 6. Efeito da variável tipo de posse sobre a ausência de artigo definido

\begin{tabular}{c|c|c}
\hline Tipo de posse & Apl/T & PR \\
\hline Partes do corpo & $2 / 3=66,7 \%$ &. $\mathbf{7 2 3}$ \\
\hline Relações pessoais & $17 / 29=58,6 \%$ & $\mathbf{. 6 5 3}$ \\
\hline Relações de parentesco & $106 / 174=60,9 \%$ & $\mathbf{. 6 4 3}$ \\
\hline Posse alienável & $9 / 21=42,9 \%$ & $\mathbf{. 5 2 6}$ \\
\hline Posse abstrata & $101 / 289=34,9 \%$ & .393 \\
\hline Relação parte-todo & $0 / 1=0$ & - \\
\hline
\end{tabular}

Fonte: Elaboração própria.

Os resultados da Tabela 6 indicam que as variantes semânticas mais favorecedoras para a ausência de artigo definido diante de pronomes possessivos são as estruturas que indicam partes do corpo (.723), as que remetem a relações pessoais (.653), as estruturas que indicam relações de parentesco (.643) e os sintagmas que representam posse alienável (.526). Contudo, não é muito seguro tecer considerações acerca da variante partes do corpo, visto que há um número pequeno de dados. A variante posse abstrata se revelou como um contexto de bloqueio para a não realização do artigo definido e, no que se refere à relação parte-todo, não houve dado de ausência de artigo diante de possessivo. A seguir, encontram-se expressos os exemplos de (7) a (10), que evidenciam a atuação das variantes que propiciam a não realização do artigo definido no contexto investigado. 
(7) Eu fiquei lá desde vinte e três horas que nós chegámos até três horas madrugada que meu pé não saiu daqui pra pisar pista de dança (ST-B-1-m)

(8) Homem já tem sua mulher (ST-C-1-h)

(9) Minha mãe disse que foi nascido aqui (ST-B-1-h)

(10) As pessoas trazem seus tecidos nós confeccionamos (ST-C-2-m)

A análise multivariável não indicou como relevante para a implementação de sintagmas sem artigos definidos a variável Frequência de uso do crioulo Forro. A hipótese inicial era de que haveria uma correlação estrita entre o emprego de sintagmas sem artigo definido e a proficiência dos informantes no crioulo Forro. Tendo em vista a não comprovação da hipótese, buscou-se realizar uma nova análise, com a observação do comportamento de cada um dos informantes que compõem o corpus, de modo a identificar se comportamentos idiossincráticos comprometeriam a seleção da variável pelo programa de análise computacional. A seguir, na Tabela 7, encontram-se expostos os índices percentuais de não realização de artigo definido relativos a cada informante.

Tabela 7. Índices de não realização de artigo definido diante de pronome possessivo (distribuição por informante)

\begin{tabular}{|c|c|c|c|c|c|c|}
\hline & \multicolumn{2}{|c|}{ Nível 1} & \multicolumn{2}{|c|}{ Nível 2} & \multicolumn{2}{|c|}{ Nível 3} \\
\hline \multicolumn{7}{|c|}{ Faixa $A$} \\
\hline $\begin{array}{c}\text { Sexo do } \\
\text { informante }\end{array}$ & masculino & feminino & masculino & feminino & masculino & feminino \\
\hline $\begin{array}{c}\text { Frequência de } \\
\text { uso do crioulo } \\
\text { Forro }\end{array}$ & $\begin{array}{l}\text { BAIXA/ } \\
\text { NULA }\end{array}$ & MÉDIA & MÉDIA & $\begin{array}{l}\text { BAIXA/ } \\
\text { NULA }\end{array}$ & $\begin{array}{l}\text { BAIXA/ } \\
\text { NULA }\end{array}$ & MÉDIA \\
\hline Apl/T & $\begin{array}{c}24 / 39= \\
61 \%\end{array}$ & $\begin{array}{c}25 / 28= \\
\mathbf{8 9} \%\end{array}$ & $\begin{array}{c}33 / 80= \\
41 \%\end{array}$ & $4 / 14=28 \%$ & $\begin{array}{c}25 / 79= \\
31 \%\end{array}$ & $\begin{array}{c}14 / 43= \\
32 \%\end{array}$ \\
\hline \multicolumn{7}{|c|}{ Faixa B } \\
\hline $\begin{array}{c}\text { Sexo do } \\
\text { informante }\end{array}$ & masculino & feminino & masculino & feminino & masculino & feminino \\
\hline $\begin{array}{c}\text { Frequência de } \\
\text { uso do crioulo } \\
\text { Forro }\end{array}$ & MÉDIA & $\begin{array}{l}\text { BAIXA/ } \\
\text { NULA }\end{array}$ & MÉDIA & MÉDIA & $\begin{array}{l}\text { BAIXA/ } \\
\text { NULA }\end{array}$ & MÉDIA \\
\hline $\mathrm{Apl} / \mathrm{T}$ & $\begin{array}{c}10 / 11= \\
90 \%\end{array}$ & $\begin{array}{c}14 / 21= \\
66 \%\end{array}$ & $\begin{array}{c}10 / 24= \\
41 \%\end{array}$ & $\begin{array}{c}8 / 22= \\
36 \%\end{array}$ & $\begin{array}{c}11 / 40= \\
27 \%\end{array}$ & $6 / 18=33 \%$ \\
\hline
\end{tabular}


- O uso variável de artigo definido diante de pronome possessivo na variedade urbana do Português de São Tomé

\begin{tabular}{|c|c|c|c|c|c|}
\hline \multicolumn{6}{|c|}{ Faixa $C^{8}$} \\
\hline $\begin{array}{c}\text { Sexo do } \\
\text { informante }\end{array}$ & masculino & feminino & masculino & feminino & masculino \\
\hline $\begin{array}{l}\text { Frequência de } \\
\text { uso do crioulo } \\
\text { Forro }\end{array}$ & ALTA & MÉDIA & $\begin{array}{l}\text { BAIXA/ } \\
\text { NULA }\end{array}$ & $\begin{array}{c}\text { BAIXA/ } \\
\text { NULA }\end{array}$ & $\begin{array}{l}\text { BAIXA/ } \\
\text { NULA }\end{array}$ \\
\hline $\mathrm{Apl} / \mathrm{T}$ & $\begin{array}{c}15 / 19= \\
78 \%\end{array}$ & $\begin{array}{l}5 / 8= \\
62 \%\end{array}$ & $6 / 14=42 \%$ & $\begin{array}{c}9 / 19= \\
47 \%\end{array}$ & $\begin{array}{c}16 / 37= \\
43 \%\end{array}$ \\
\hline
\end{tabular}

Fonte: Elaboração própria.

Dois traços morfossintáticos do Forro poderiam influenciar o emprego de artigos definidos na norma são-tomense. O primeiro, já mencionado em seções anteriores, se vincula à não existência de um sistema de artigos definidos nessa língua. O segundo diz respeito à existência, no Forro, de uma forma demonstrativa, "se", que ora pode funcionar como propriamente um demonstrativo, ora pode desempenhar a função de artigo definido (FERRAZ, 1979). Em função dessas propriedades, havia uma expectativa de que o índice percentual de ausência de artigo diante de possessivo, presente na Tabela 2, fosse maior - principalmente no comportamento dos falantes que se identificam como falantes do Forro em variadas situações de interação - uma vez que o uso do crioulo Forro poderia exercer influência no uso do artigo em Português, inibindo a sua presença.

No entanto, conforme exposto na Tabela 7, a configuração do corpus (há somente um informante que reconhece utilizar mais o crioulo Forro do que o Português) não permitiu comprovar se, de fato, a coexistência entre as duas línguas condicionaria a não realização de artigo definido diante de possessivos na variedade são-tomense. Os resultados presentes na Tabela 7 revelam muito mais uma influência da escolarização no emprego de artigos definidos diante de possessivos.

Os informantes menos escolarizados não são sensíveis às pressões da norma reforçada pela escola, o que se reflete no favorecimento da variante ausência de artigo definido. Esse comportamento é verificado inclusive em análises sobre outras variedades do Português faladas em São Tomé (FIGUEIREDO, 2019). No conjunto de dados analisados neste artigo, a questão do trânsito do falante entre o Português e o Forro deve cumprir um papel secundário na dinâmica da regra variável. Esse resultado pode ser decorrente da própria estrutura da amostra, que não é equilibrada em termos do preenchimento das células relativas ao domínio das línguas locais.

8 A célula relativa à informante do sexo feminino com nível superior completo está vazia porque não havia, na ocasião de recolha dos inquéritos, informantes que se enquadrassem nesse perfil. 


\section{Reflexões finais}

O trabalho descrito neste artigo tinha por objetivo investigar se, de fato, na variedade são-tomense, haveria variação no emprego de artigos definidos diante de sintagmas possessivos. Os dados revelam, efetivamente, que o emprego do artigo definido nesse contexto morfossintático se configura como uma regra variável. Os resultados estatísticos indicam que a variedade são-tomense apresenta uma dinâmica distinta, no que se refere a essa variável, do que a observada no Português Europeu, que se caracteriza como sua norma de referência: na variedade europeia, a presença de artigo diante de pronomes possessivos é uma regra categórica, com violação apenas em contextos discursivopragmáticos bastante específicos. As análises realizadas neste trabalho revelaram que a variedade urbana do PST apresenta um comportamento mais próximo às tendências observadas na variedade do Português do Brasil, em que a realização variável de artigo é saliente entre as regiões.

No que se refere à análise variável, das onze variáveis independentes postuladas para a investigação apenas quatro se revelaram estatisticamente relevantes para a não ocorrência de artigos definidos diante de possessivos. Mostraram-se relevantes para a ausência de artigo a escolaridade do informante, o tipo de sintagma, a função sintática do sintagma em que figura o pronome possessivo e o tipo de posse.

Com relação à variável que buscava verificar o papel do contato entre línguas no comportamento de artigos diante de possessivos, a frequência de uso do crioulo Forro não foi um condicionamento selecionado como relevante para a ausência de artigo nos dados da variedade são-tomense. Tal resultado frustrou as expectativas iniciais, uma vez que se partiu da hipótese de que na variedade urbana do PST a ausência de artigo definido no contexto investigado poderia ser a variante mais provável por influência do Português Europeu e também por influência do contato entre o Português e o Forro. O Forro, de acordo com Ferraz (1979) e Lucchesi (1993), não apresenta um sistema de artigos definidos, embora conte uma partícula demonstrativa que, eventualmente - e de acordo com situações muito específicas - pode assumir o mesmo papel morfossintático desempenhado pelos artigos.

De forma a buscar explicações para a não seleção do condicionamento que trata da relação de contato entre as línguas, procedeu-se a uma nova análise, com a investigação do comportamento de cada um dos informantes que compõem a amostra. A estrutura do corpus - a amostra não é equilibrada no que se refere à distribuição dos falantes em termos de Português como língua materna ou língua segunda, além de contar com apenas um informante que se identifica como falante prototípico do crioulo Forro - não tornou 
- O uso variável de artigo definido diante de pronome possessivo na variedade urbana do Português de São Tomé

possível verificar se a coexistência de ambas as línguas no mesmo território poderia exercer influência quanto ao uso de artigo, inibindo sua presença na variedade aqui investigada.

Os resultados da análise do comportamento do informante revelaram, de forma consistente, a influência da escolaridade do informante (que foi a primeira variável independente selecionada pelo programa de análises estatísticas). Dessa maneira, este trabalho traz uma contribuição importante para a descrição de um fenômeno variável fartamente descrito em variedades do Português e revela a necessidade de novas perspectivas de investigação, seja na reformulação das hipóteses, seja na organização de corpora que sejam mais equilibrados no que se refere à distribuição dos falantes quanto à aquisição do português e à proficiência no crioulo Forro. A investigação apresentada neste artigo tem suas limitações, e os resultados aqui discutidos são importantes para revelar o panorama de uma variedade africana do Português, cuja descrição vem despertando cada vez mais o interesse da comunidade científica.

\section{Referências}

AFONSO, H. L. Interferências linguísticas: um contributo para o ensino da língua portuguesa em S. Tomé e Príncipe. 2009. Dissertação (Mestrado em Língua Portuguesa) Faculdade de Letras, Universidade de Lisboa, Lisboa, 2009.

BAXTER, A.; LOPES, N. O artigo definido. In: LUCCHESI, D.; BAXTER, A.; RIBEIRO, I. (org.). O Português Afro-Brasileiro. Salvador: EdUFBA, 2009. p. 319-330.

BAXTER, A.; LOPES, N. Bare definite reference NPs in an afro-brazilian portuguese dialect. Revista Internacional de Lingüística Iberoamericana, Madrid, v. 4, n. 1, p. 55-69, 2006.

BAXTER, A.; LOPES, N. O artigo definido em variação com zero no SN de referência específica: re-estruturação em três variedades do português. Comunicação apresentada no XIV Congresso Internacional ALFAL - Associación de Linguística e Filología de América Latina, Monterrey, México, 17-21 de outubro, 2005.

BRANDÃO, S. F. Variação e o estatuto de variedades do Português. Diadorim, Rio de Janeiro, v. 18, n. esp., p. 83-104, 2016.

CALLOU, D.; SILVA, G.M. O. O uso do artigo definido em contextos específicos. In: HORA, D. da (org.). Diversidade Lingüística no Brasil. João Pessoa: Idéia, 1997. 
FERRAZ, L. I. The creole of São Tomé. Johannesburg: Witwatersrand University Press, 1979.

FERRAZ, L. I. The origin and development of four creoles in the Gulf of Guinea. African Studies, London, v. 35, n. 1, p. 33-38, 1976.

FIGUEIREDO, C. F. G. Uso variável do artigo definido no português da comunidade de Almoxarife, São Tomé. Journal of Ibero-Romance Creoles, Lisboa, v. 9, n. 1, p. 358-389, 2019.

GONÇALVES, R.; HAGEMEIJER, T. O Português num contexto multilíngue: o caso de São Tomé e Príncipe. Revista Científica da Universidade Eduardo Mondlane. Moçambique, v. 1, n. 1, p. 87-107, 2015.

INSTITUTO NACIONAL DE ESTATÍSTICA. INE: São Tomé e Príncipe em números. 2012. Disponível em: https://www.ine.st/index.php/publicacao/documentos/file/343-12caracteristicas-educacionais-da-populacao-recenseamento-2012. Acesso em: 28 ago. 2021.

INVERNO, L.; SWOLKIEN, D. O artigo definido zero em dois contextos específicos no português do Brasil e no crioulo de Cabo Verde. Biblos. Coimbra, I, p. 179-192, 2003.

LABOV, W. Principle of linguistic change. v. 2: social factors. Oxford: Blackwell Publishing, 2001.

LABOV, W. Principle of linguistic change. v. 1: internal factors. Oxford: Blackwell Publishing, 1994.

LABOV, W. Sociolinguistic patterns. Philadelphia: University of Pennsylvania Press, 1972.

LEITE, Y.; CALLOU, D. Como falam os brasileiros. 4. ed. Rio de Janeiro: Zahar, 2010.

LORENZINO, G. Uma avaliação socio-linguística sobre São Tomé e Príncipe. In: DUARTE, I.; LEIRIA, I. (org.). Actas do Congresso Internacional sobre o Português. v. II. Lisboa: Associação Portuguesa de Linguística /Edições Colibri, p. 435-449, 1996.

LUCCHESI, D. The article systems of Cape Verde and São Tomé creole portuguese: general principles and specific factors. Journal of Pidgin and Creole Languages, Amsterdam, v. 8, n. 1, p. 81-108, 1993. 
- O uso variável de artigo definido diante de pronome possessivo na variedade urbana do Português de São Tomé

LUCCHESI, D.; BAXTER, A. A transmissão linguística irregular. In: BAXTER, A.; LUCCHESI. D.; RIBEIRO, I. (org.). O português afro-brasileiro. Salvador: EdUFBA, 2009. p. 101-124.

MAGALHÃES, T. V. O uso de artigo definido diante de pronome possessivo em textos portugueses do século XVI a XIX. Leitura, Maceió, v. 1, n. 47, p. 123-143, jun. 2011.

MENON, O. P. S. Presença/ausência de artigos diante de nomes próprios no português do Brasil (PB). In: ANAIS DO V ENCONTRO DA REDE SUL LETRAS. Tubarão. Anais ... UNISUL, p. 729-738, 2016.

SANTIAGO, A. M.; AGOSTINHO, A. L. Situação linguística do português em São Tomé e Príncipe. A cor das Letras, Feira de Santana, v. 21, n. 1, p. 39-61, 2020.

SCHEl, A. O artigo definido frente a pronomes possessivos na literatura brasileira do século XIX. Revista da ABRALIN, v. 8, n. 2, p. 15-44, jul./dez. 2009.

SILVA, G. M. O. Estudo da regularidade na variação dos possessivos no português do Rio de Janeiro. 1982. Tese (Doutorado em Linguística). Rio de Janeiro: Faculdade de Letras/UFRJ, 1982.

THOMASON, S. G.; KAUFMAN, T. Language contact, creolization and genetic linguistics. Berkeley: University of California Press, 1988.

WEIREICH, U. Languages in contact: findings and problems. New York: Mounton, 1953.

WEINREICH, U.; LABOV, W.; HERZOG, M. Fundamentos empíricos para uma teoria da mudança linguística. Tradução Marcos Bagno. São Paulo: Parábola, 2006 [1968].

WINFORD, D. An introduction to contact linguistics. Oxford: Blackwell Publishing, 2003.

COMO CITAR ESTE ARTIGO: GOMES, Danielle Kely; CORDEIRO, Livia Rodrigues. O uso variável de artigo definido diante de pronome possessivo na variedade urbana do Português de São Tomé. Revista do GEL, v. 18, n. 3, p. 95-114, 2021. Disponível em: https://revistadogel.gel.org.br/

Submetido em: 28/07/2021 | Aceito em: 30/08/2021. 